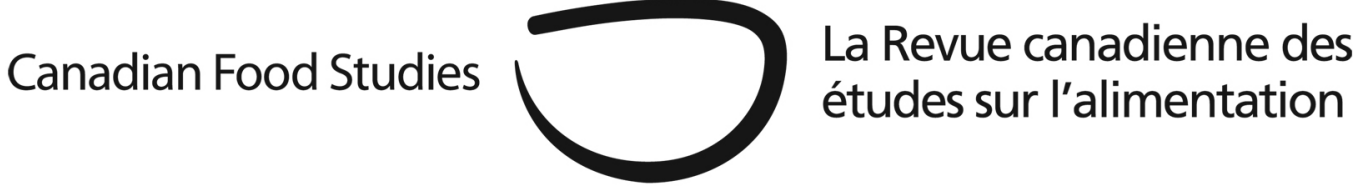

Original Research Article

\title{
Finding formula: Community-based organizational responses to infant formula needs due to household food insecurity
}

\author{
Lesley Frank* \\ Acadia University
}

\begin{abstract}
This paper reports on qualitative research concerning community-based organizational responses to infant formula needs due to household food insecurity. It explores this topic against the backdrop of neo-liberal social welfare approaches that shape gendered food work within food insecure households, as well as current state approaches to infant feeding policy targeted to vulnerable populations. Based on telephone interviews with a random sample of organizations across Canada ( $\mathrm{N}=26)$ in 2016, this paper details typical responses to infant food insecurity within a sample of family resource projects with funding from the Canada Prenatal Nutrition Program, as well as typical responses from a sample of food banks. Results demonstrate that neither state nor community organizations adequately respond to infant food insecurity. This leads to serious problems of unequal access, potential food risk, and food injustice that are imposed on mothers and formula-fed infants when mothers are forced into situations of pathologized foraging to find formula. This paper argues that infant food insecurity is the result of a succession of public policy failures that are best addressed with a reflexive, feminist, food justice approach.
\end{abstract}

Keywords: food studies, feminist studies, sociology, social welfare, infant food insecurity 


\section{Introduction}

Infant food insecurity, as a food justice issue, is shaped by intersecting inequality dynamics at the heart of constrained food production labour, food acquisition work, and the feeding work primarily done by mothers. Despite the fact that Food Studies as a field is concerned with questions of food production and consumption, infant food insecurity, which embodies both, is notable in its neglect within the field as a topic of study. I argue that the reason for this neglect is that infant feeding labour is socially constructed as gendered social reproduction work. The assumption is that, under the right circumstances, women can actively produce food via their breasts. However, such food production and feeding labour does not come easily for all mothers, particularly mothers in poverty. Poverty, itself highly gendered, is at the heart of infant food insecurity, for which poor mothers are held responsible.

Infants are food secure when they have access to a sustainable food system - a system that depends on the economic, nutritional, social, and cultural support of mothers as producers of food through breastfeeding. When breastfeeding is not possible for biological and social reasons, there must then be access to reliable, safe, affordable, and personally acceptable alternatives through socially just means. Currently in Canada, poverty and household food insecurity introduce vulnerabilities in both breastfeeding and access to breast milk alternatives when they are highly priced, unaffordable, or difficult to access (Frank, 2015). In Canada, it is mothers and infants together who most suffer the outcomes of this social issue. However, the negative health consequences of nutrition inequity in the early years will ultimately be of considerable cost to society.

This paper details what can occur when the state fails to provide adequate income security for those parenting young children, creating a heavy burden on mothers to maintain family income while being largely responsible for food and care work. Qualitative research in Nova Scotia (Frank, 2015) documented that, in the absence of income security, mothers struggled to maintain an adequate supply of formula and routinely turned to food banks and community organizations for help. Finding formula was fraught with challenges. Mothers were often not successful in securing what they needed, or were forced to use products they knew might not be tolerable for their baby. Some resorted to stealing formula when it could not be found through charity sources. Food insecurity created situations of pathologized foraging for formula when this food product was largely inaccessible, when the mother did not know where to go for it, and when charity needed to be relied on.

However, when mothers with infant food insecurity issues turn to community-based organizations across Canada, what does the landscape of organizational responses look like? Drawing from interviews with a sample of family resource programs and food banks, this paper describes typical organizational responses to infant formula needs and distribution practices, and the formal and informal policies and values that shape if, and how, formula is made available to food insecure mothers (and, at times, other caregivers). Based on this research, this paper argues that a succession of public policy failures has created serious problems of unequal access, 
potential food risk, and food injustice that are imposed on food insecure formula-feeding mothers and formula-fed infants when the mothers are forced into pathologized foraging situations to find formula. Community-based organizations present divergent responses, politics, and values concerning their responsibility to respond as well as how to respond. In particular, this research sheds light on how a reflexive, feminist, food justice approach at the community organizational level offers a vision for addressing the injustice of infant food insecurity at the state level of maternal income and food security and infant feeding policy.

\section{Background}

\section{The gendered nature of infant feeding and infant food insecurity}

Infant feeding practice occurs within the social and family relations of feeding and eating that are typical of gendered divisions of labour. Early work by DeVault (1991) and Charles and Kerr (1986) argues that feeding work is socially constructed as part of the expected caring work of mothers, which is primarily invisible and is often experienced as oppressive. More recent research on family food practices in Canada upholds this claim of implicit gender assumptions about women’s food work (Beagan, Chapman, D’Sylva, \& Bassett, 2008; Cairns \& Johnson, 2015). Breastfeeding, as a component of family food work, is impossible to detach from female responsibility due to its biological imperative. Thus, feeding infants, in comparison to feeding others, is arguably more enshrined in ideas about women's natural dispositions for family food work. As an expression of femininity, such work has been experienced both as oppressive and as an important marker of identity through which many women find meaning and power (Allison, 1991; Belasco, 2008; Cairns \& Johnson, 2015). This dichotomy of oppression versus power is also central to feminist debates about breastfeeding. While some see breastfeeding as a feminist practice where women should have the right (and support) to exercise their power to breastfeed and produce food (Van Esterik, 1999), others utilize feminist arguments to illuminate breastfeeding as a form of oppressive labour (Bem, 1993; Chodorow, 1978), or breastfeeding promotion as a moral crusade harmful to women (Knaak; 2005; Kukla, 2006; Lee, 2008; Murphy, 2000; Wallace \& Chason, 2007). Jung (2015) claims that breastfeeding promotion “crosses the line into lactivism” (p. 7), which is discriminatory in the use of government resources when only mothers who breastfeed receive state support in feeding their babies.

Debates about breastfeeding and non-breastfeeding practice and breast milk substitutes are also central in the limited literature about infant food insecurity. Some argue that breastfeeding ensures food security for infants (Huffman, Rasmusson, Newman, \& O’Gara, 1992; Infact Canada, 2004; Lawrence, 2007), and constitutes a sustainable food system (Bertmann \& Yaroch, 2016). This argument extends to food insecurity associated with breast milk substitutes in terms of non-affordability (Infact Canada, 1997), negative nutritional outcomes (Jelliffe \& Jelliffe, 1978; Palmer, 2009), and problems of food safety due to 
contamination and preparation issues (Greiner, 2009; Lakshman, Ogilvie, \& Ong, 2009; Weir, 2002). Van Esterik (1999) offers a more nuanced analysis of food insecurity surrounding infant feeding when she positions it as a right-to-food issue, or one that reflects upon intersecting rights of mother and infant: the right to food, the right to feed, and the right to be fed that "occurs within a culturally defined sexual division of labor and set of gender assumptions” (p. 225). I argue that household food insecurity, linked to overlapping systems of oppression, is a social constraint that impinges on such rights, impeding breastfeeding and optimal formula feeding alike.

Intersectionality theory highlights the need to examine phenomena, paying attention to how systems of oppression interact for different groups of people (Crenshaw, 1989). Sociological and anthropological research that has identified the social constraints of infant feeding has illustrated intersectionalities of gender, race, cultural background, and social class that affect mothers' decisions and outcomes concerning infant feeding practice (see Maher, 1992; Smith, Hausman, \& Labbok, 2012). Breastfeeding success is linked to the social position of women in society, which sexualizes the breast, impedes public breastfeeding, and poses contradictions between breastfeeding and paid employment (Wallace \& Chason, 2007). Additionally, women experience breastfeeding in different ways, and rates of initiation and duration differ by cultural/racial background, education level, Aboriginal status, and marital status (Health Canada, 2010).

There are social gradients in rates of breastfeeding initiation and exclusive breastfeeding duration in Canada. While breastfeeding initiation rates are currently high in Canada overall at 87.3 percent in 2009-2010, fewer mothers (81 percent) in the lowest income quintile initiated breastfeeding, and rates increase in each subsequent quintile (Health Canada 2010). There are significantly lower rates of breastfeeding initiation among Aboriginal women in Canada (77.8 percent) compared to non-Aboriginal mothers (88 percent), yet other cultural/racial groups (93.5 percent of Asian mothers, 86.7 percent of Black mothers, and 89.4 percent of mothers who have immigrated to Canada within the last five years) have higher breastfeeding initiation rates compared to White mothers (86.7 percent). While Canada can boast relatively high breastfeeding initiation rates across all income groups and cultural/racial groups (except for Aboriginal mothers), rates for exclusive breastfeeding to six months are much lower, only ranging from 26.9 percent (in the lowest income quintile) to 33.3 percent (in the highest income quintile). The rates of exclusive breastfeeding by cultural/racial group show a similar pattern to breastfeeding initiation, whereby Asian (30.2 percent) and Black mothers (27 percent) have higher rates than White mothers (25.8 percent), recent immigrants (28.2 percent) have higher rates than nonimmigrant mothers (24.7 percent), and Aboriginal mothers (16.6 percent) have the lowest rates.

While there appear to be differences in breastfeeding trends based on socio-economic as well as cultural factors, how income and cultural/racial identities come together to shape infant feeding practice in Canada is not well understood. Breastfeeding statistics limit our understanding, because group aggregates cluster together what might be very different culturalbased infant feeding histories and preferences. As well, nutrition surveillance statistics only 
capture a limited reality of infant feeding practices: breastfeeding initiation includes trying to breastfeed even for a short time, exclusive breastfeeding excludes those that almost exclusively breastfed or used mixed feeding strategies, and there are no Canadian statistics that capture formula feeding practices. We do not know the extent to which Canadian mothers, even those that breastfeed, rely on formula to feed their babies. Qualitative research in Canada (Frank, 2015; Partyka, Whiting, Grunerud, Archibald, \& Quennell, 2010) reveals the importance of poverty and food insecurity as barriers to breastfeeding continuation, intertwined with other factors (such as cultural and family histories, social environments, and available support) that show how infant feeding, like all food practice, embodies complex social relations beyond, but intertwined with, issues related to poverty.

\section{The Canadian state and feeding the baby}

Understanding the complexity of these social relations also requires examining the Canadian state and how public policy might shape the work of feeding the baby, which is one piece of the overall work of socially reproducing Canadian society. Social reproduction involves "a range of activities, behaviors, responsibilities, and relationships that ensure the daily and generational social, emotional, moral, and physical reproduction of people” (Bezanson, 2006, p. 175). Food provisioning is one of the tasks of social reproduction and, like social reproduction more broadly, is highly gendered in most societies. Bezanson (2006), in detailing the relations between gender, household insecurity, and neo-liberalism in the 1990s in Ontario, showed how neo-liberal social welfare reform, away from strong state provisioning for social reproduction, meant weaker state support and greater responsibility for women and the non-profit sector for the provision of these needs. This same pattern of neo-liberal welfare reform occurred across the country, with several notable negative effects on women and mothers, and even more so on poor mothers. Since the mid-1990s, income assistance policy has moved toward a "workfare” policy approach (Evans, 2006) whereby mothers may experience limited maternity protection from the requirement to seek or engage in employment as a condition of income security entitlements (Evans, 2006). The shift to "workfare" is built on problematic gendered assumptions: that women can find and sustain jobs in the labour market, that these jobs will pay well enough to alleviate families' poverty, and that it is possible to manage the dual responsibilities of waged work and family caregiving (Scott, London, \& Myers, 2002) with a lack of affordable and accessible childcare. Furthermore, neo-liberal social welfare states assume that care work, including feeding the baby, is a family responsibility, increasingly "excised from the sphere of state responsibility" (Braedley, 2006, p. 216).

Accomplishing the work of social reproduction without adequate income is a challenge, and women, particularly racialized, immigrant, and Aboriginal women in Canada, are more likely to experience poverty (Canada Without Poverty, 2017). Women in Canada as a whole have lower employment participation rates, are less likely to work full time (Statistic Canada, 2017), and still experience a gender pay gap that is the seventh-largest among OECD countries 
(Organisation for Economic Co-operation and Development, 2014). Women's access to employment insurance and maternity leave, linked to longer breastfeeding duration (Statistics Canada, 2005), has declined over time because women are more likely to have non-standard work arrangements, which makes meeting the eligibility criteria more challenging (Townsend \& Hayes, 2007).

Neo-liberal social welfare reform is also typified by a shift from governments delivering public programs directly to steering — setting policy and overseeing community nongovernmental organizations to provide social reproduction work (Chappell, 2010). While some organizations receive core and project funding to deliver key social welfare programs (e.g., child welfare, early parenting support, and childcare), there is also an increase in voluntary associations and faith-based organizations providing basic social services to the poor (Poppendieck, 1998), illustrated by the rise of food banks in Canada as a response to food insecurity. Such community-level food work is extensive and has become an integral component of the welfare state (Thériault \& Yadlowski, 2000). However, research has shown that food banks lack the capacity to adequately respond to the food needs of users (Tarasuk \& Eakin, 2003), and the invisibility of unmet needs and the mere existence of food banks are barriers to real solutions to food insecurity as a social problem in need of government intervention (Power, 2011; Riches, 1997; Tarasuk \& Eakin, 2003).

There is no governmental infant food security policy in Canada per se. Policy related to infant feeding primarily falls into health policy domains, whereby the protection and support of breastfeeding, and the regulation of infant formula, is a matter of public policy. Health Canada led the establishment of the Breastfeeding Committee for Canada, which, in 1996, became the national authority for the Baby-Friendly Initiative (BFI) (Breastfeeding Committee for Canada, 2012). The BFI aims to facilitate the implementation of initiatives and resolutions to support breastfeeding, which include the aims and principles of the 1981 World Health Organization (WHO) International Code of Marketing of Breast-milk Substitutes (referred to as the Code), through "health promotion, education and collaboration, rather than through legislation or regulations” (Breastfeeding Committee for Canada, 2012, p. 5). Canada's BFI was adapted from the WHO/UNICEF Baby-Friendly Hospital Initiative (World Health Organization, 1991). The term 'baby-friendly' refers to protecting, promoting, and supporting breastfeeding, partly through adherence to The Code. The Code stipulates how to handle the distribution of donated and discounted formula, which is used as a marketing strategy by formula companies and is known to negatively affect breastfeeding duration and exclusivity (Rosenberg, Eastham, Kasehagen, \& Sandoval, 2008). The Code stipulates that healthcare organizations should not be used to promote formula or to display information about formula, and that donated or low-price formula provided to institutions or organizations "should only be used or distributed for infants who have to be fed on breast-milk substitutes” (World Health Organization, 1981, p.11). Additionally, the Code stipulates, "where donated supplies of infant formula or other products within the scope of this Code are distributed outside an institution, the institution or organization should take steps to ensure that supplies can be continued as long as the infants concerned need 
them” (World Health Organization, 1981, p.12). Despite low numbers of hospital and community health services achieving the Baby-Friendly Accreditation status in Canada, the recommendations of the Code have shaped infant feeding policy throughout the healthcare system and in community practice. In Canada, while an infant may receive formula within a healthcare organization, there is no state financed system for the distribution of infant formula outside of healthcare institutions. This is despite the Code recognizing that there is "a legitimate market for infant formula and for suitable ingredients for which to prepare it: and that these products should accordingly be made accessible to those who need them through commercial or non-commercial distribution system; and that they should not be marketed or distributed in ways that may interfere with the protection and promotion of breastfeeding” (World Health Organization, 1981, p. 10). Additionally, Infact Canada, a national organization committed to protecting, promoting, and supporting breastfeeding, has criticized charity-provided formula at food banks as violating the Code (Infact Canada, 2005) as they consider such free distribution a form of marketing, and therefore not Baby-Friendly, and that charity systems cannot ensure that supplies can be continued for as long as they are needed. Infact Canada has publicly denounced Food Banks Canada for its corporate partnership with the infant formula company Nestlé (Infact Canada, 2014). Foodbanks Canada's response, posted on Infact Canada’s website, states that they have never received formula donations from Nestlé for distribution, but rather that they use Nestlé's financial donations for programing.

Formula needs are supported indirectly and minimally by governments through food entitlement cash transfers for children on welfare; however, not all welfare policy includes food entitlements for children. Provincial and territorial welfare programs include some special diet allowances, but infant formula may not be considered a special need unless medically indicated. The Canadian approach to income security broadly, and to maternal/infant programs specifically, differs from other similar high-income countries in its relative lack of targeted food entitlements. In Canada, unlike in the United States and the United Kingdom, there are no state-provided food entitlement programs for infants, either federally or provincially. The Women, Infants, and Children program (WIC) in the United States, an income entitlement program that promotes and works to protect breastfeeding within low-income populations, also provides food supplementation for infants and children (United States Department of Agriculture, 2015). The UK Healthy Start Program is a similar income-targeted program that aims to improve the health of pregnant women and families by providing vouchers that can be used to purchase milk, fruits and vegetables, and infant formula (UK Healthy Start, 2017). While the National Child Benefit in Canada is in place to support the costs of raising children, cash transfers are not targeted to food. They may be used for other household needs such as rent and heat, particularly in families receiving income assistance, when shelter allowances are inadequate to cover the real costs of housing. The Canadian Prenatal Nutrition Program (CPNP) managed by the Public Health Agency of Canada (PHAC), like the US WIC program and the UK Healthy Start Program, is a national program with the objective to support vulnerable pregnant and postnatal women (Public Health Agency of Canada, 2007). However, PHAC, in agreement with critics of the WIC 
program (see Kent, 2006), is concerned that free formula distribution will negatively affect mothers' choices of feeding methods and lessen breastfeeding initiation rates (Public Health Agency of Canada, 2014).

CPNP programs operate throughout selected communities across the country, offering, but not ensuring, entitlement to prenatal and postnatal support. Programming within projects is influenced through funding agreements with PHAC, whereby there is a steering of infant-feeding policy toward a uniform position on promoting and supporting breastfeeding as the sole nutrition strategy for vulnerable populations. These centres do not have a mandate or resources to respond to the infant formula needs of food insecure families. However, because their mandate is to work with vulnerable women concerning early infancy support, including infant feeding, they are well positioned to be aware of needs, and may be the primary source of support for families struggling with such issues. CPNP has as a core value that they are community-based and therefore embrace community development principles of responding to local needs. However, the need for formula due to poverty, although experienced within communities, is strongly advised against and is not addressed within the current funding arrangements and infant feeding policy directives of PHAC. PHAC itself recognizes the dilemmas faced by organizations in this regard, and has responded with a practical guidebook entitled Protecting, Promoting, and Supporting Breastfeeding: A Practical Workbook for Community Based Programs (Public Health Agency of Canada, 2014). Within, a suggested response for infant food security is provided:

Women who come to community based programs are often faced with financial or food insecurity that affects their ability to buy formula. Rather than giving formula directly, a better use of resources could include providing food, food coupons, recipes and ingredients, good food boxes and encouraging collective buying and community gardens.

These approaches put "Mothers and Babies First" [emphasis original], help decrease the stress of food shortages, and free up the family's own money to buy formula if needed [emphasis original]. Still, in spite of these strategies, staff sometimes see women who are desperately short of resources, and they fear for the adequacy or appropriateness of the baby's diet. In these situations, it is best to work with partners whose work is less directly tied to the protection, promotion and support of breastfeeding and develop an emergency response approach for babies at risk. Referral to a family physician, paediatrician, and/or dietitian may be appropriate. Linking the mother with the local health unit and area food banks [emphasis added] may also be helpful. (Public Health Agency of Canada, 2014, p. 18)

When it comes to infant food insecurity, it is evident that the government, while somewhat supporting food supplementation for families, is endorsing a culture of food charity 
for infants, rather than state entitlement for food. How do CPNP projects experience and navigate this "practical dilemma" of infant food insecurity? Are food banks an appropriate solution, and are they able to meet needs? Further, how might these organizational responses affect infants and mothers who are ultimately held responsible for accomplishing the social reproduction labour of feeding the baby in food insecure conditions in Canada?

\section{The current study: Methods}

An exploratory qualitative methodology was used to research the question, "What is the current state of practice, policy, and opinion regarding free infant formula provisioning in Canada from the perspective of community-based organizations?" Semi-structured telephone interviews were conducted with staff from CPNP projects and food bank organizations across Canada to explore this research question. Two interviews, one from each organization type within each province and territory, were conducted with staff $(\mathrm{N}=26)$. Organizations were selected using a criterionbased random sampling process, the purpose being to provide a geographically dispersed snapshot. Organizations were selected within each province from two lists compiled by organization type. The sample of CPNP interviews was drawn from a list of all CPNP programs funded by the Public Health Agency of Canada, and the food bank sample was drawn from a list provided by Food Banks Canada. Despite samples being selected randomly within each jurisdiction, they are not necessarily representative of the population of these organizational types due to the small sample size. However, the intent of this qualitative research was not to generalize to the population, rather it was to explore typologies of organizational types based only on the sample. A larger sample size may have revealed additional organizational types.

The interviewees were not recorded. Rather, the interviewer completed a form with standardized questions that probed for information on formal and informal policy concerning infant formula availability and distribution. All interviewees were asked about their perspective on the food insecurity of non-breastfed infants in their area. They were asked if mothers and/or caregivers were ever in need of emergency infant formula, if they came to them for help in finding formula, the extent to which formula affordability was an issue for mothers, and whether their organization responded to this need if presented. Questions also included whether formula was available for free at other local community places, and whether there was a perceived need for emergency or habitual infant formula locally due to food insecurity. Data analysis began by transcribing handwritten responses into a spreadsheet by organizational type. Subsequently, responses were examined by sorting responses for each question, and compiled data were coded for the identification of typical cases of organizational types. Coding was completed using a three-step process. First, open coding was conducted, whereby notes are read line by line to distinguish all potentially relevant information concerning the research question. Second, these open codes were grouped into four broad categories that explain organizational approaches to meeting infant formula needs: practices, policy approach, values orientation, and expressed 
symbolic meaning of infant formula. Finally, typical organizational cases were constructed based on the varying responses in these four categories, and two continuums of organizational responses were created. Typical case construction does not imply that all family resource programs or food banks within the sample, or in Canada, fit perfectly into one of these cases. This does mean that there was a tendency for policy, values, practice, and formula symbolism to align in the ways described within this sample.

\section{Results}

\section{Family resource programs with CPNP funding}

Figure 1: Continuum of CPNP Organizational Responses to the Food Insecurity of the Formula Fed Infant

\begin{tabular}{|c|c|c|c|}
\hline We don't do that & $\begin{array}{l}\text { We support formula } \\
\text { needs on the down low }\end{array}$ & We provide infant formula & Practice \\
\hline $\begin{array}{l}\text { Adherence to } \\
\text { PHAC BF Directives }\end{array}$ & $\begin{array}{l}\text { Ambiguous adherence to PHAC } \\
\text { BF Directives }\end{array}$ & $\begin{array}{l}\text { Adoption of Site Specific } \\
\text { Infant Feeding Policy that } \\
\text { includes food security }\end{array}$ & $\begin{array}{l}\text { Policy } \\
\text { Approach }\end{array}$ \\
\hline Baby-Friendly & Baby-Friendly and Mother Centred & $\begin{array}{l}\text { Baby-Friendly, Mother Centred, } \\
\text { Food Justice Centred }\end{array}$ & $\begin{array}{l}\text { Values } \\
\text { Orientation }\end{array}$ \\
\hline Unhealthy; failure & Unhealthy; failure; trouble & Food for survival & $\begin{array}{l}\text { Symbolic meaning } \\
\text { of formula }\end{array}$ \\
\hline
\end{tabular}

Continuum of organizational responses

Figure 1 depicts the analysis of family resource interview data, showing a continuum of responses to infant formula needs. It displays three typical organizational cases along a practice continuum justified by organizational policies (steered by policy directives of funders) as well as by expressed values about the role of organizations in supporting mothers and/or caregivers, and feelings about infant formula as a food product. 


\section{We don't do that-we promote and support breastfeeding}

On one end of the practice continuum were organizations that never responded to formula needs. As one interviewee said, "We are breastfeeding friendly here. People sometimes give us formula they don't need, but we don't keep it. We give it to the food bank.” If a mother presented to them with this need, the mother would be referred to another community resource, the most noted being food banks. However, it was common that, when asked about availability of formula at these places, staff did not always know if formula was available there. This practice stance was justified by adherence to baby-friendly policy. This approach is in line with directives from PHAC.

\section{We promote and support breastfeeding-but we support infant food security "on the down low"}

The most typical organizational practice in response to the food insecurity of formula-fed infants was to help "on the down low." This meant adherence to baby-friendly policy in that there was no overt formula distribution, no use of CPNP funding for infant food supplementation, and no formula "visibly" on site. However, individual staff helped mothers to "find formula" through either "passed along" formula that was given to them, or occasionally by buying it personally. One interviewee said, "Yes, we respond to this need, but formula is not something we have or keep on hand.” Another said, "If people are not using formula, they bring it in, but we don't promote formula. We will take formula, and if people are in an emergency we will give it to them, but we don't put it on display." Because there was no consistent source of formula to be found, when staff were approached for formula, it was common for them to seek formula on mothers' behalf, and/or to refer mothers to other potential resources such as food banks, women's centres, local doctors, social service offices, or, in one instance, a local pharmacy that was known to sell formula at cost when mothers were in need.

Organizations supporting mothers “on the down low” expressed a more ambiguous adherence to baby-friendly policy, justified by being breastfeeding friendly, but having a “women-centred value system.” Formal policies that prohibit formula distribution governed their work, yet their ethics of wanting to support all mothers led to clandestine support of formula feeding because of concern for mothers' welfare and infant hunger. This was expressed as “We are breastfeeding friendly but..." statements. For example, "We are breastfeeding friendly but we are also women-centred,” and, "We are a breastfeeding friendly place, but we support all families in what they need. There are mothers that can't breastfeed, so I don't turn formula away." However, the conflict staff felt between baby-friendly policy and being women-centred in wanting to support all mothers drove their work underground to avoid potential conflict with other breastfeeding groups in their area and because of fear of funding implications. As one interviewee said, "We don't tell anyone. Helping mothers access formula is a 'real hot topic' at BFI meetings.” She went on to describe how local Indigenous women in the neighbouring 
reserve had been able to get coupons for free formula; however, that had stopped due to pressure from the BFI committee. She said, “We don't want to get in trouble so we are very sneaky about helping people with formula. The BFI people don't know what we do here-we are breastfeeding friendly, but we are realistic. I have hidden cans of formula under my desk when I know that certain people might be dropping by."

\section{We promote and support breastfeeding and infant food security}

On the other end of the continuum, two centres routinely presented with infant food insecurity matters revealed that they respond overtly and formally via secured external funding (outside of CPNP funding - one from the provincial government, one from a non-profit foundation) in order to be able to address ongoing emergency formula distribution. Additionally, one centre, which primarily served African Canadian participants, routinely received donated formula from a formula company, maintaining a consistent supply which they provided to mothers when needed. These interviewees felt that protecting, promoting, and supporting breastfeeding needed to coexist with supporting the food insecure infant. This practice was justified by a feminist, womenand baby-friendly, food justice values orientation. One interviewee shared her organization's own infant feeding policy that attempted to reconcile these values, additionally sharing her opinion about class-based and race-based assumptions within breastfeeding policy, by saying,

Making formula accessible is a debate that has been going on in the area for years. There is resistance to making formula accessible. How do we support those moms? We can't make them ashamed for using formula. Affording formula is a huge challenge for these families if they are on assistance. It is not very often that they can find formula in the food bank. There has been a big increase in rent costs. The housing market is crazy, and people won't rent to families with kids. We have adopted a project-specific infant feeding policy that addresses the need to support the formulafeeding mother and infant, we meet mothers where they are at, and we recognize that babies need to eat and have a right to food. Our policy states: All women will be encouraged and supported with whichever form of infant feeding she has chosen. No one should be denied food. We shouldn't leave it up to society to dictate what our needs are. So often breastfeeding policy feels like middle class, white family policy.

Finally, when discussing organizational practices, interviewees displayed feelings about infant formula as a food, revealing how food is enshrined with symbolic meaning. Because a project's breastfeeding rates are tracked as an indicator of project success, organizations that never facilitate formula distribution in many ways tended to demonize formula as a food product, and the formula-feeding mother/formula-fed infant was symbolic of program goal failure. In discussions about the programs provided, breastfeeding promotion was central. In some projects, 
postnatal food supplementation was available only to breastfeeding mothers, and celebrations for breastfeeding milestones took place where breastfeeding incentives were given. As one interviewee stated when describing their breastfeeding incentive of a free haircut, "Mom is being good to baby, so we are good to Mom." Non-breastfeeding mothers did not receive the same support, implying that not breastfeeding is not as good as breastfeeding, and is unhealthy for the baby. Breastfeeding incentives were evident despite the fact that PHAC steers projects away from these practices because of inconclusive evidence that such incentives are effective in supporting the continuation of breastfeeding, and non-breastfeeding mothers may be led to feel judged for not breastfeeding (PHAC, 2014). Finally, the organizations that subversively passed along formula appeared to display similar symbolic meanings concerning formula, as they too worried about project success measured in terms of breastfeeding rates. They additionally saw formula as "trouble," as one interviewee jokingly spoke about needing to hide it, but also trouble in that it represented value conflicts over supporting and protecting breastfeeding while wanting to be intersectionally feminist by addressing all mothers' needs. However, organizations that boldly provided formula to address infant food insecurity enshrined formula with different meaning. Here, formula was just food—a necessity for survival—and providing it was symbolic of a commitment to food justice.

\section{Food banks}

While practice directives from PHAC (2014) state that linking mothers with area food banks may be helpful in addressing infant food insecurity, this research found that food banks themselves are inconsistent in addressing this issue. This sample of food banks reported diverse governance structures and organizational capacities. Food banks exist outside of government funding, providing for a social welfare need not governed by state policy. Therefore, food provisioning within charity organizations falls outside of nutrition policy (including infant feeding policy). Additionally, how food is provided is broadly shaped by the nature of charity, in which meeting needs is contingent on the limits of benevolence of individual donors but also of local resource availability; it is therefore limited by both the economic capacity of individual donors and the availability of food supply, which is in turn shaped by a myriad of social, economic, and political relations that may differ by region. The food items to be found on food bank shelves are shaped by these localized and more distant relations. What will individuals donate? What will organizations publicly ask for both during donation drives and routinely on their websites, should they exist? What will corporate donors donate to food banks, and what is their motivation to do so? If monetary donations are secured, what food items are chosen to be purchased by food bank volunteers/staff, and what are the values shaping these decisions? All of these factors shape whether infant formula is available in food banks.

Figure 2 depicts four typical organizational cases concerning practice responses to infant formula needs from the sample of food bank interviewees. It also presents both formal and 
informal policy concerning infant formula distribution, as well as expressed values and feelings about infant formula as a food product.

Figure 2: Continuum of Food Bank Organizational Responses to Food Insecurity of the Formula Fed Infant

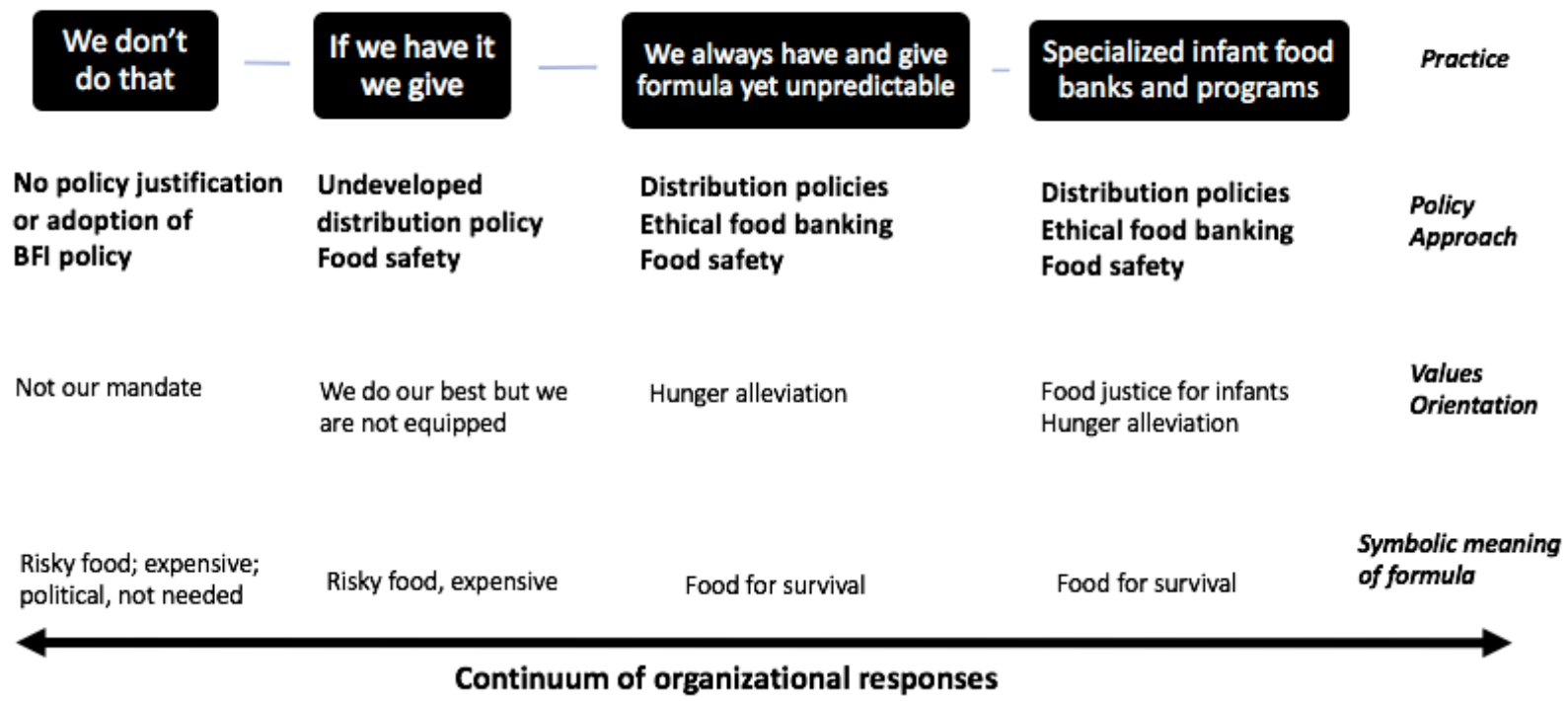

We don't do that-it is not a focus of our operation

One end of the practice continuum represents food banks that indicated they never have infant formula available. Reasons provided were varied. One food bank interviewee said, "We never have formula in stock, we refer people to the women's centre.” This interviewee explained that donated formula was risky, because it was usually close to its expiration date. Also, formula was less likely to be donated because it was expensive. Another food bank interviewee stated that the food bank never had infant formula because another organization in the local community was better equipped to provide this support, which he felt required special expertise. He said, "We are not set up to do that. Other places have a system - we pass it on.” A third food bank interviewee stated that they never had formula because a board member advocated a breastfeeding policy agenda. She said, "The food bank sometimes receives donations of infant formula, but we send them to [a central food bank] for distribution. This is because one of the food bank board members is also a member of the BFI and wants the community to be breastfeeding friendly." These food banks did not respond to the needs of the food insecure infant, even though the first principle of the Ethical Foodbanking Code of Food Banks Canada states that food banks will "Provide food and other assistance to those needing help regardless of race, national or ethnic origin, citizenship, colour, religion, sex, sexual orientation, income source, age [emphasis added], or mental or physical ability” (Food Banks Canada, 2017). 
If we have it, we give it—and mothers take what they can get

Other food bank interviewees stated that they occasionally had formula passively acquired through donations. Relying on donations presented unique problems concerning the availability of formula in terms of type and supply. One interviewee said, "We occasionally get formula donations from the local grocery store, but stores have a tendency to hold onto the products because they are so pricey. They mark them down rather than donate them." Purchasing formula was not possible because of the high cost and a lack of resources. One interviewee said, "We do not really advertise that formula is available because we would never be able to provide it to everyone that might need it, and we have been reprimanded before for having it on display by someone that works at the hospital." One interviewee said, "We have had to refuse people formula before because we didn't have the right formula in stock. It would be difficult if you had a child with any type of diet restrictions - they would be out of luck." Another said, "Even though we had formula, there have been times when a mother wasn't able to use it because it wasn't the right type.” Thus, the type of formula that was there was unpredictable and random (variable brands, powder or liquid, and of no particular developmental stage). Interviewees explained that, if it is there, mothers must take what is on offer, even if it is not the type their infant needs. One interviewee said, "We get many types of formula donated, and people take different types when they need to." If formula is not there, mothers need to be referred elsewhere, but generally interviewees could not name a specific place that would be a reliable source.

While having no informal or formal policies against formula distribution, organizations did not have policies concerning its distribution, such as how much, how often, and what products are provided. In terms of policy, The Ethical Foodbanking Code that states the need for non-discrimination based on age was not mentioned; the focus was only on policy concerning food safety that specified expiration dates, as formula was perceived as risky.

We always have formula-it is necessary for infant hunger alleviation

Similarly, other food bank organizations experienced limitations to the types of infant formula available, and often received formula close to its expiration date. However, some organizations indicated that they always had some formula available, as they made concerted efforts to maintain their supply either through specific donor requests, food drives, or support from umbrella food bank organizations. Keeping a consistent supply was necessary, as it was common to get referrals from government programs, and these food banks were committed to the value of addressing infant hunger in line with the Ethical Foodbanking Code. They also paid close attention to food safety regulations. One interviewee stated that maintaining a formula supply was easy, as "people like to address child hunger," but another interviewee noted that, while "people are generous in their donations of formula, you have to ask for it. They don't think about 
it until they are asked.” Another said, "We always have formula in stock, but we never buy it, it is all reclaimed from stores, thus close to expiry date.”

These organizations developed a range of distribution policies, whereby some provided a limited amount for a short time frame, while others preferred to forgo setting limits for infants. It was common for only one or two brands or types of formula to be available. Infant formula seemed to take on a variety of meanings in these organizations. For some, it was merely ageappropriate food, necessary for infant survival. However, it also took on a meaning of "high exchange value" that required careful surveillance to avoid fraudulent use. One organization had an informal policy to "scratch out" the barcode on the cans of formula to render the "expensive" product non-exchangeable for another product or for cash. Another food bank adopted the informal policy of refusing powdered infant formula to single men, because it was common in the area for drug dealers to mix it with cocaine. Men asking for formula were told, "Get the mother to come back and ask for it." Still another food bank would not provide formula to caregivers outside of the immediate family, such as grandparents, saying, "We won’t supply the food for when kids are coming for a visit.”

\section{Specialized infant food banks and infant food programs}

On the other end of the continuum, some organizations developed specialized infant food programs, like the emergency infant food programs found in the CPNP sample, that overtly addressed infant food insecurity. As one interviewee said, "We run an infant nutrition program. We recognize that infants are also living in poverty, and nutrition is important in the early years. What we care about is that a baby can eat." One organization referred to itself as running an Infant Food Bank that provided several baby care and food products. Two other organizations operated a special infant food program as part of a larger food bank operation. Both infant food banks and programs operated with adjusted distribution policies tailored to the specific needs of infants. These organizations also routinely received referrals from government (e.g., Public Health) and other community programs because they were known for their work in addressing infant food insecurity.

A range of formalized distribution policies were noted, specifying amounts of food and frequency of allowable use as well as invoking the Ethical Foodbanking Code. Food safety concerning infant foods was a priority, whereby one interviewee said, "We purchase all infant foods because everything related to baby food cannot be expired, compared to food in cans. When it comes to kids, we have to be careful." Another interviewee said, "We would never use reclaimed formula in our program," and another said, "We receive a large supply from donations so as not to be close to expiration." Such organizations expressed a range of values behind their approach. As mentioned, infant hunger alleviation was central, but so was the value of food justice. One interviewee stressed how their program was different from those of other organizations that called themselves infant food banks in the area, which she claimed were not operating with food justice values, but rather were anti-choice pregnancy centres. 


\section{Discussion}

This research shows that family resource programs funded by CPNP do not have a formal mandate to address infant food insecurity, yet many are routinely approached for such support. Three typical organizational responses to infant food insecurity were found. The current mismatch between practice, policy, and values represented by these data appears to do little to address the needs of the formula-feeding mother, or formula-fed infant, in all but a few cases that sought funding outside of CPNP. Infant feeding policy in Canada is largely aimed at shaping the feeding behaviours of mothers through education, rather than implementing an incomeentitlement-based approach that could support feeding labour for successful breastfeeding, or food access for infants when breastfeeding does not occur. CPNP's directive on how to address infant food insecurity is through helping to supplement the mother's and/or family's food, but not the infant's, suggesting that breastfeeding is the sole response to infant food insecurity. Mothers who formula feed must deal with infant food insecurity on their own or be referred to agencies with a different policy stance (e.g., food banks). This research shows that this suggested response was the path most frequently chosen by CPNP projects in this sample. However, in many instances, an underlying feminist value position prevailed and support was provided, albeit in secret. On the one hand, feminist values support breastfeeding. On the other hand, there is a deep commitment to helping all mothers regardless of how they feed their baby, recognizing the challenges the mothers confront: poverty, desperation around their responsibility to feed, and the shame they experience foraging for formula. The women workers are caught between a personal feminist ideology of care and the relations of ruling (Smith, 1996) mediated by agency policies that do not necessarily meet the best interests of their participants. A lack of power causes them to work subversively. On the surface, the organizations meet needs, but this research shows the powerlessness of the women workers and the masking of conflicting values and problematic agency policies.

This research also shows that food banks operate on a continuum of responses supported by diverse value orientations, and were thus unreliable in addressing infant food insecurity. Some food banks do not openly request formula donations; others rarely have formula donated as it is a high cost food commodity, rendering formula availability inconsistent, unpredictable, and random. Both mothers and infants are subjected to pathologized foraging for formula from organizations that present very divergent responses, politics, and values concerning the responsibility to respond to this need.

There are numerous factors at play that work together to create the conditions for infant food insecurity: current neo-liberal approaches to social welfare in the areas of income security and maternity protection (which are particularly harmful to mothers who hold most of the responsibility for food work); the intersecting oppressions of gender, class, and race that affect poverty rates and infant feeding experiences; "lactivist" infant feeding policy; the dominance of food charity as the Canadian response to food needs; and contested social meanings embedded in infant formula. Such conditions are the result of a succession of public policy failures, which 
include: 1 . Weak income security policy/programs and maternity protection for early parenting that result in high rates of household food insecurity, leading to compromised breastfeeding and the non-affordability of infant formula; 2. Lack of state support for infant food security, as demonstrated by an absence of income-tested food entitlements or income supplementation during maternity and early infancy; and 3. Ineffective food-charity-based community responses to infant food insecurity, which place a heavy burden on mothers as they deal with the challenge of being caught in debates about how they should be feeding their babies, while they navigate the challenges of feeding their babies at all.

There is a history of tension between supporting breastfeeding and making formula more readily available, and feminist arguments are used to support both sides. Breastfeeding policy, in particular the Baby-Friendly Initiative, significantly shaped the CPNP responses to infants' formula needs, but only one food bank organization mentioned this policy as an influence on their practices. In fact, when probed, several food bank interviewees expressed shock that providing formula would be viewed as problematic. A few food bank and CPNP organizations stated clearly that, despite their practices, policies, and values about breastfeeding, failing to provide a consistent, adequate supply of formula was unjust and a violation of the right to food. DuPuis, Harrison, and Goodman (2011) point out that people often operate using very different definitions of justice, and they advocate for a reflexive approach, "one with a clear understanding of the complexities of justice in terms of its various and contradictory meanings” (p. 284). They state that "reflexivity is not a set of values, but a process by which people pursue goals while acknowledging the imperfection of their actions. It is also not a particular, fixed process, but one that responds to changing circumstances, imperfectly, but with an awareness of the contradiction of the moment” (DuPuis et al., 2011, p. 297). I heard this reflexive process at work during the interviews as each interviewee justified, or tried to justify, organizational practice: "I know we are not supposed to be doing this, but...” It is time to bring this often-difficult reflexive, feminist, food justice approach into our public discussions of how to address infant food insecurity. A food justice agenda recognizes the ways in which the intersecting oppressions of gender, race and ethnicity, and social class contribute to the food insecurity of mothers and infants. This research shows that a feminist, food justice approach to infant food insecurity would be a more compassionate and comprehensive way of meeting the food needs of poor mothers and infants. As one interviewee said, "The bottom line is that infants need food and have a right to food, full stop."

A few CPNP projects developed systems to help food insecure mothers feed babies. This work was about feeding hungry babies, and in doing so represented food justice work that was not at odds with the organization's breastfeeding policies. In fact, this food justice work was a clearer interpretation of the International Code of the Marketing of Breastmilk Substitutes, which recognizes the need for formula and stresses that "these products should be made accessible to those who need them through commercial or non-commercial distribution systems," and that those involved with supplying formula should "take steps to ensure that supplies can be continued as long as the infants concerned need them” (World Health Organization, 1981, p. 12). 
These organizations were responding to the problem that food insecure mothers experience a non-affordable commercial system, and there is no adequate non-commercial distribution system. Furthermore, they did so despite the fact that creating such a system is likely to face resistance from those that conceptualize any free distribution (even if purchased through "normal procurement channels" in line with the Code) as harmful to the promotion and protection of breastfeeding. However, these CPNP projects provide insight into how being both feminist and food justice oriented addresses the value conflicts that surround infant food insecurity. Some food banks shared this food justice position; however, only one food bank justified their work as aligning with feminist values, despite the fact that it was mothers who show up at the food bank door.

On a practical note, are these emergency food systems the best way to address this food justice issue? While community-based services and resources do much to support mothers in the daily struggles of feeding the baby, CPNP projects do not have the mandate or the funding to address infant food insecurity, and piecemeal food charity offerings are inadequate for sound infant feeding. The reality that mothers seek help from food banks and family resource centres for infant food needs is a result of household food insecurity, brought on partly by inadequate state supports for early parenting. Having infant food insecurity addressed through communitybased food charity models throughout Canada does not create the economic security and social conditions necessary for successful breastfeeding or formula feeding. While some organizations have developed "better" systems, upstream approaches positioned in federal and provincial jurisdictions are better suited to address the many structural barriers to breastfeeding and optimal formula feeding. Federal considerations, such as adequate maternity leave benefits and maternalinfant food entitlement programs (i.e., UK Healthy Start Program), should be explored. Evaluating the effectiveness of existing provincial income supplement entitlement programs (i.e., Newfoundland and Labrador's Mother and Baby Nutrition Supplement and New Brunswick's Pre/Postnatal Benefit Program) to improve household food insecurity and infant feeding outcomes would be one step toward this. Failing to make upstream shifts in policy will continue to obscure the serious problems of unequal food access, potential food risk, and food injustice that mothers and infants experience when the mothers are forced into pathologized foraging for formula.

\section{References}

Allison, A. (1991). Japanese mothers and "obentos": The lunch-box as ideological state apparatus. Anthropological Quarterly, 64(4), 195-207.

Beagan, B., Chapman, G., D’Sylva, A., \& Bassett, B. P. (2008). 'It's just easier for me to do it': Rationalizing the family division of food work. Sociology, 42(4), 653-671.

Belasco, W. (2008). Food: Key concepts. Oxford-New York: Berg Publishers. 
Bem, S. L. (1993). The lenses of gender: Transforming the debate on sexual inequality. New Haven, CT: Yale University Press.

Bertmann, F., \& Yaroch, A. (2016). Role of breast milk and breastfeeding within the context of a sustainable, resilient food system. Journal of Hunger \& Environmental Nutrition, 11(2), 242-253.

Bezanson, K. (2006). The neo-liberal state and social reproduction: Gender and household insecurity in the late 1990s. In K. Bezanson \& M. Luxton (Eds.), Social reproduction: Feminist political economy challenges neo-liberalism (pp. 173-214). Montreal: McGillQueen's University Press.

Braedley, S. (2006) Someone to watch over you: Gender, class and social reproduction. In K. Bezanson \& M. Luxton (Eds.), Social reproduction: Feminist political economy challenges neo-liberalism (pp. 215-230). Montreal: McGill-Queen’s University Press.

Breastfeeding Committee for Canada. (2012). The Baby-Friendly Initiative (BFI) in Canada. Retrieved from http://breastfeedingcanada.ca/documents/BFI_Status_report_2012_FINAL.pdf

Cairns, K. \& Johnson, J. (2015). Food and femininity. London: Bloomsbury.

Canada Without Poverty. (2017). Just the facts. Retrieved from http://www.cwpcsp.ca/poverty/just-the-facts/

Chappell, R. (2010). Social welfare in Canadian society. Toronto: Nelson.

Charles, N., \& Kerr, M. (1986). Food for feminist thought. Sociological Review, 34(3), 537-572.

Chodorow, N. (1978). The reproduction of mothering: Psychoanalysis and the sociology of gender. Berkeley: University of California Press.

Crenshaw, K. (1989). Demarginalizing the intersection of race and sex: A black feminist critique of antidiscrimination doctrine, feminist theory and antiracist politics. University of Chicago Legal Forum, 139-167.

DeVault, M. (1991). Feeding the family. Chicago: University of Chicago Press.

DuPuis, E. M., Harrison, J., \& Goodman, D. (2011). Just food? In A. Hope \& J. Agyeman (Eds.), Cultivating food justice: Race, class, and sustainability (pp. 283-307). London: MIT Press.

Evans, P. (2006). Eroding Canadian social welfare: The Mulroney legacy, 1984-1993. In R. Black \& J. Keshen (Eds.), Social fabric or patchwork quilt: The development of social policy in Canada. Toronto: Broadview Press. 
Food Banks Canada. (2017). Ethical Foodbanking Code. Retrieved from https://www.foodbankscanada.ca/About-Us/Organization/Food-Banking-Code-ofEthics.aspx

Frank, L. (2015). Exploring infant feeding practices in food insecure households: What is the real issue? Food and Foodways, 23(3), 186-209.

Greiner, T. (2009). Beyond melamine: More reasons not to use animal milk in infant formula. Journal of Human Lactation, 25(4), 397-399.

Health Canada. (2010). Trends in breastfeeding practices in Canada (2001-2008). Retrieved from http://www.hc-sc.gc.ca/fn-an/surveill/nutrition/commun/prenatal/trends-tendanceseng.php

Huffman, S. L., Rasmusson, E., Newman, V., \& O’Gara, C. (1992). Breastfeeding: A natural resource for food security. Washington: Wellstart International, USAID Cooperative Agreement No. DPE-5966-A-00-1045-00.

Infact Canada. (1997). The cost of formula and infant feeding security. Retrieved from http://www.infactcanada.ca/security.htm

Infact Canada. (2004). Breastfeeding and food security. Retrieved from http://www.infactcanada.ca/Breastfeeding_and_Food_Security.pdf

Infact Canada. (2005). Food banks and infant formula. Retrieved from http://www.infactcanada.ca/Action_Alert_Dec9_05.htm

Infact Canada. (2014). Sample letter to Food Banks Canada warning against their dangerous partnership with Nestlé. Retrieved from http://infactcanada.ca/food-banks-canada-nestleletter.html

Jelliffe, D. B., \& Jelliffe, E. F. P. (1978). Human milk in the modern world. Oxford: Oxford University Press.

Jung, C. (2015). Lactivism: How feminists and fundamentalists, hippies and yuppies, and physicians and politicians made breastfeeding big business and bad policy. New York: Basic Books.

Kent, G. (2006). WIC’s promotion of infant formula in the United States. International Breastfeeding Journal, 1, 8.

Knaak, S. (2005). Breast-feeding, bottle-feeding and Dr. Spock: The shifting context of choice. The Canadian Review of Sociology and Anthropology, 42(2), 197-216.

Kukla, R. (2006). Ethics and ideology in breastfeeding advocacy campaigns. Hypatia, 21(1), $157-181$. 
Lakshman, R., Ogilvie, D., \& Ong, K. (2009). Mothers’ experiences of bottle-feeding: A systematic review of qualitative and quantitative studies. Archives of Disease in Childhood, 94, 596-601.

Lawrence, R. (2007). The eradication of poverty one child at a time through breastfeeding: A contribution to the global theme issue on poverty and human development October 22, 2007. Breastfeeding Medicine, 2(4), 193-194.

Lee, E. (2008). Living with risk in the age of 'intensive motherhood': Maternal identity and infant feeding. Health, Risk \& Society, 10(5), 467-477.

Maher, V. (1992). Breast-feeding and maternal depletion: Natural law or cultural arrangements? In V. Maher (Ed.), The anthropology of breast-feeding: Natural law or social construct (pp. 151-180). Providence RI: Berg Publisher Ltd.

Murphy, E. (2000). Risk, responsibility, and rhetoric in infant feeding. Journal of Contemporary Ethnography, 29(3), 291-325.

Organisation for Economic Co-operation and Development. (2014). Gender equality. Retrieved from https://www.oecd.org/gender/data/genderwagegap.htm

Palmer, G. (2009). The politic of breastfeeding. London: Printer \& Martin Ltd.

Partyka, B., Whiting, S., Grunerud, D., Archibald, K., \& Quennell, B. (2010). Infant nutrition in Saskatoon: Barriers to infant food security. Canadian Journal of Dietetic Practice and Research, 71(2), 79-84.

Poppendieck, J. (1998). Sweet charity? Emergency food and the end of entitlement. New York: Penguin.

Power, E. (2011, July 25). It is time to close Canada’s food banks. The Globe and Mail. Retrieved from http://www.theglobeandmail.com/commentary/its-time-to-close-canadasfood-banks/article587889/

Public Health Agency of Canada. (2007). The Canada prenatal nutrition program: A decade of promoting the health of mothers, babies and communities. Her Majesty the Queen in Right of Canada, represented by the Minister of Health.

Public Health Agency of Canada. (2014). Protecting, promoting, and supporting breastfeeding: A practical workbook for community based programs. Retrieved from http://www.phacaspc.gc.ca/hp-ps/dca-dea/publications/pdf/ppsb-ppsam-eng.pdf

Riches, G. (1997). Hunger, food security and welfare policies: Issue and debates in first world societies. Proceedings of the Nutrition Society, 56, 62-74.

Rosenberg, K., Eastham, C., Kasehagen, L., \& Sandoval, A. (2008). Marketing infant formula through hospitals: The impact of commercial hospital discharge packs on breastfeeding. American Journal of Public Health, 98(2), 290-295. 
Scott E., London, A., \& Myers, A. (2002). Dangerous dependencies: The intersection of welfare reform and domestic violence. Gender \& Society, 16(6), 878-897.

Smith, D. (1996). The relations of ruling: A feminist inquiry. Studies in Culture, Organizations, and Society, 2(2), 171-190.

Smith, P., Hausman, B., \& Labbok, M. (Eds.) (2012). Beyond health, beyond choice: Breastfeeding constraints and realities. New Brunswick: Rutgers University Press.

Statistics Canada. (2005). Breastfeeding practices. Health Reports, 6(2), 23-31. Retrieved from http://www.statcan.ca/english/freepub/82-003-XIE/0020482-003-XIE.pdf

Statistics Canada. (2017). Paid work. Retrieved from http://www.statcan.gc.ca/pub/89-503x/2010001/article/11387-eng.htm

Tarasuk, V., \& Eakin, J. M. (2003). Charitable food assistance as symbolic gesture: An ethnographic study of food banks in Ontario. Social Science \& Medicine, 56, 1505-1515.

Thériault, L., \& Yadlowski, L. (2000). Revisiting the food bank issues in Canada. Canadian Social Work Review, 17(2), 205-223.

Townsend, M., \& Hayes, K. (2007). Women and the employment insurance program. Canadian Centre for Policy Alternatives. Retrieved from http://www.policyalternatives.ca/sites/default/files/uploads/publications/National_Office Pubs/2007/Women_and_the_EI_Program.pdf

UK Healthy Start. (2017). Healthy Start. Retrieved from https://www.healthystart.nhs.uk.

United States Department of Agriculture - Food and Nutrition Services. (2015). Women, infants, and children (WIC). Retrieved from http://www.fns.usda.gov/wic/aboutwic/wicataglance.htm

Van Esterik, P. (1999). Right to food, right to feed, right to be fed: The intersection of women's rights and the right to food. Agriculture and Human Values, 16, 225-232.

Wallace, L. E., \& Chason, H. (2007). Infant feeding in the modern world: Medicalization and the maternal body. Sociological Spectrum, 27(4), 405-438.

Weir, E. (2002). Powdered infant formula and fatal infection with Enterobacter sakazakii. Canadian Medical Association Journal, 166(12), 1570.

World Health Organization. (1981). International code of marketing of breast-milk substitutes. Retrieved from http://www.who.int/nutrition/publications/code_english.pdf

World Health Organization. (1991). The baby-friendly hospital initiative (BFHI). Retrieved from http://www.who.int/nutrition/topics/bfhi/en/index.html 